\title{
The risk of musculoskeletal disorders due to repetitive movements of upper limbs for workers employed in hazelnut sorting
}

\author{
Andrea Colantoni, Massimo Cecchini, Danilo Monarca, Roberto Bedini, Simone Riccioni \\ Department of Agriculture, Forest, Nature and Energy (DAFNE), University of Tuscia, Italy
}

\begin{abstract}
In the agro-industrial sector there are many activities whose urgent rhythms can cause a considerable exposure to bio-mechanical risk factors. In the hazelnut sorting, the workers are subject to several biomechanical risks, with repetitive movements, and operations that require a remarkable degree of strength. A thorough study of the workers' exposure to repetitive manual movements has been carried out, with the aim of setting up the necessary measures to reduce the risk factors. The aim of the research is to assess the risk of work-related musculo-skeletal disorders (WMSDs) due to repetitive work, for workers employed to hazelnut shells sorting. The research was carried out in an agricultural cooperative in the Viterbo's area. For risk assessment authors used a method (Occupational Repetitive Actions "OCRA" index according to ISO 112283:2009, Ergonomics - Manual handling - Part 3: Handling of low loads at high frequency) which keeps into consideration several risk factors (such as repetitiveness, prehension force, posture). The risk was assessed for 16 female workers (in eight workplaces and in two different shifts) through this classification: workers with experience less than 1 year, from 1 to 10 years and more than 10 years. This classification is very important for knowing if the professional experience could be considered a "prevention measure" for the risk reduction. The results show a high risk level for the right and left limb. The factors which more have contributed to reach such risk level are the great number of movements and the lack of recovering time.
\end{abstract}

Correspondence: Massimo Cecchini, Department of Agriculture, Forest, Nature and Energy (DAFNE), University of Tuscia, Via S. Camillo de Lellis snc, 01100 Viterbo, Italy.

Tel. +39.0761.357.357 - Fax: +39.0761 .357 .453 .

E-mail: ergolab@unitus.it

Key words: repetitive movements, hazelnut, ergonomics, manual sorting.

Contributions: the authors contributed equally.

Conflict of interests: the authors declare no potential conflict of interests.

Conference presentation: part of this paper was presented at the $10^{\text {th }}$ Italian Conference AIIA (Associazione Italiana di Ingegneria Agraria), 2013 September 8-12, Viterbo, Italy.

(C) Copyright A. Colantoni et al., 2013

Licensee PAGEPress, Italy

Journal of Agricultural Engineering 2013; XLIV(s2):e130

doi:10.4081/jae.2013.s2.e130

This article is distributed under the terms of the Creative Commons Attribution Noncommercial License (by-nc 3.0) which permits any noncommercial use, distribution, and reproduction in any medium, provided the original author(s) and source are credited.

\section{Introduction}

The upper limbs have an extremely mobility adapted to human necessities. These common movements are not particularly harmful in the ordinary activities of daily life.

Muscle contraction without sufficient recovery time causes pain as a consequence of lactic acid accumulation, irritating substance. Workrelated musculoskeletal disorders (WMSDs) include muscle, tendon and nerve injuries in the shoulder, elbow, forearm, wrist and hand that are not caused by acute trauma (ACGIH, 2001).

Repetitive movements of upper limb and lack of recovery time identified in manual hazelnut sorting could be a risk for WMSDs (Colantoni $e t$ al., 2012). A review by the National Institute for Occupational Safety and Health (NIOSH) of epidemiological studies related to WMSDs in the workplace has pointed out their association with the following workplace factors: 1) heavy physical work, 2) lifting and forceful movements, 3) bending and twisting (awkward postures), and 4) exposure to wholebody vibration. Recent innovations at a structural and organizational level, introduced by the European laws, have effectively led to an overall drop, over the last ten years, of the number of injuries and professional diseases. However, although there has been a decrease for "traditional" pathologies, such as hypoacusis, there has been a remarkable increase of musculoskeletal disorders, caused mainly by the lifting and transport of heavy weights, wrong working positions (extreme postures and/or sudden movements) and repetitive movements (INAIL, 2012).

Disorders by repetitive movements represent the main cause of mus culoskeletal injuries of workers, which exceeds the number of injuries caused by machinery. WMSDs include carpal tunnel syndrome, tendonitis of the shoulder and wrist, lateral epicondylitis, and others, generally of an etiologic origin. The ISO 11228-3:2009 standard establishes ergonomic recommendations for repetitive work tasks involving the manual handling of low loads at high frequency. It provides guidance on the identification and assessment of risk factors commonly associated with handling low loads at high frequency, thereby allowing evaluation of the related health risks to the working population.

In the agro-industrial sector there are many activities whose urgent rhythms can cause a considerable exposure to bio-mechanical risk factors. In the hazelnut postharvest sector the workers are subject to several biomechanical risks, with repetitive movements, and operations that require a remarkable degree of strength. A thorough study of the workers' exposure to repetitive manual movements has been carried out, with the aim of setting up the necessary measures to reduce the risk factors.

The aim of this research is to assess the risk of musculoskeletal disorders due to repetitive work, for workers employed in manual sorting of hazelnut.

\section{Materials and methods}

This study was carried out with the collaboration of Cooperative of 
Nut Producers "Colli Cimini and Sabatini" (Capranica, Italy). The establishment is set in an area of 30,000 square meters, and is equipped with modern machinery for all processes.

In the hazelnuts processing cycle, sorting is undoubtedly a fundamental operation. This operation consists in a selection of in-shell hazelnuts and allows to obtain:

full hazelnuts and empty shells (reject);

well formed hazelnuts, with no apparent deformation;

healthy hazelnuts, free of parasites and of defects that can affect the shelf life of the fruit;

clean hazelnuts, free of any visible foreign matter;

dry hazelnuts, free of abnormal external moisture.

Sorting is carried out manually on a conveyor belt (Figure 1) and the operators are standing. Figure 2 shows the block diagram of workstations.

At the aim of the research we assessed the risk for 4 workers (all of them women) of several ages. In Table 1 we can see the number of worker and the ratio age/number of years of work in the company.

The survey was conducted for workers representative of low, medium and high experience: respectively workers n. 1 (low experience), 9 (mid-low experience), 10 (mid-high experience) and 8 (high experience).

There are many ergonomics analysis tools that claim to accurately measure variables associated with WMSDs. They are essentially based on biomechanical, epidemiological and physiological approaches and identify work activities that might cause WMSDs. These tools include: Occupational Safety and Health Administration (OSHA) checklist (Schneider, 1995), Strain Index (Moore and Garg, 1995), American Conference of Governmental Industrial Hygienists (ACGIH) Hand Activity Level (HAL) (ACGIH, 2001), Outil de Repérage et d'Evaluation des Gestes (OREGE) (INRS, 2000), Rapid Upper Limb Assessment (RULA) (McAtamney and Nigel Corlett, 1993) and Occupational Repetitive Actions (OCRA) Index (Occhipinti and Colombini, 1996). For risk assessment authors used the OCRA index method, according to ISO 11228-3:2009, Ergonomics - Manual handling - Part 3: Handling of low loads at high frequency. This method keeps into consideration several risk factors (repetitiveness, prehension force, posture).

Table 1. Workers employed in manual sorting of hazelnuts.

\begin{tabular}{lc} 
Worker n. & Age/n. years of work \\
1 & $19 / 0$ \\
2 & $45 / 1$ \\
\hline 3 & $51 / 23$ \\
4 & $58 / 27$ \\
\hline 5 & $52 / 30$ \\
6 & $57 / 24$ \\
\hline 7 & $55 / 30$ \\
8 & $58 / 28$ \\
\hline 9 & $49 / 16$ \\
10 & $51 / 20$ \\
\hline 11 & $50 / 2$ \\
12 & $48 / 2$ \\
\hline 13 & $51 / 2$ \\
14 & $43 / 10$ \\
\hline 15 & $50 / 20$ \\
16 & $28 / 1$ \\
\hline
\end{tabular}

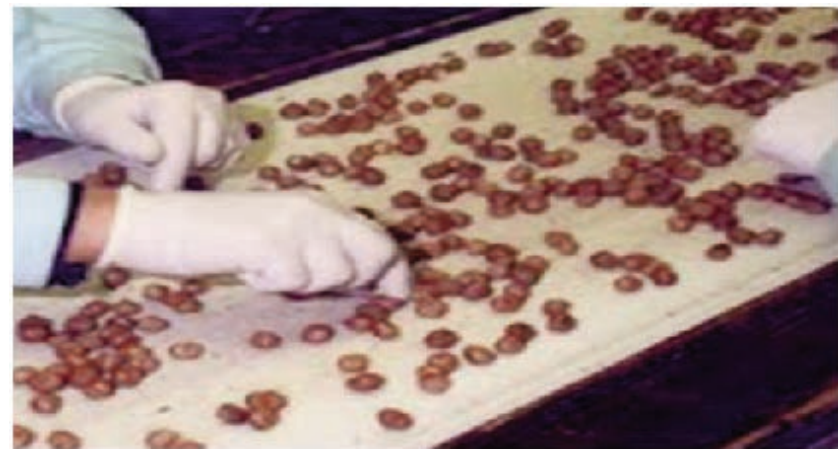

Figure 1. Manual sorting: the product passes on a conveyor belt.
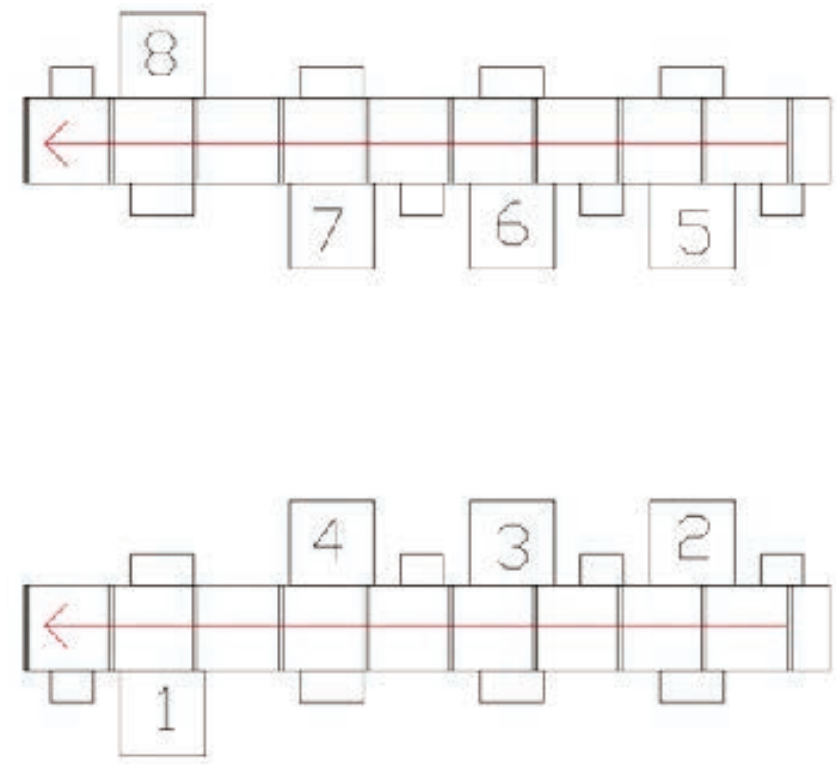

Figure 2. Block diagram of workstations.

The model is based on three requirements: 1) to thoroughly evaluate the contribution of different multiple risk factors; 2) to develop an index to evaluate the type of risk for various jobs, so that it is possible to compare different indexes and measure the changes should the work shift be re-planned; 3 ) to determine the repetitive movements of the upper limbs and the maximum frequency of actions per minute recommended in good conditions.

The "exposure index" (OCRA index) is defined by the ratio:

OCRA index $=\frac{A T A}{\text { RTA }}$

where ATA is the overall number of actual technical actions needed in the workers' shift, and RTA is the overall number of reference technical actions (i.e., the total number of actions recommended so as not to expose the workers to risks) in the shift. According to EN 1005-5:2007, an index value of 3.5 means that $95 \%$ of $P A$ (persons affected) values in the exposed worker population are expected to be higher than twice the 50th percentile $(P A=3.7 \times 2=7.4 \%)$ of the reference (not exposed) population. The $R T A$ is obtained from the following equation:

$R T A=C F \times F G M \times P O M \times A d M \times \operatorname{Re} M \times(D \times R c M \times D u M)$ 
where $C F$ is the "constant of frequency" of technical actions per minute recommended in good conditions; FoM, PoM, AdM, and ReM are multiplicative coefficients, relative to each of the $M$ jobs carried out by the worker, with values ranging between 0 and 1 , chosen according to the behaviour of the risk factors force (FoM), posture (PoM), additional factors $(A d M)$, and repetitiveness (ReM); $D$ is the net duration of the repetitive task in minutes; $R c M$ is the multiplier for the "lack of recovery period" risk factor, ranging between 0 and 1 ; and $D u M$ is the multiplier for the overall duration of repetitive tasks during a shift.

The number of actions recommended for the calculations of the OCRA index ( $C F$ in Eq. 2) is at present 30 actions per minute, although this could vary when more precise experimentation data are available. However, a particularly high frequency of technical actions, for example 40 per minute, is only tolerable for short-term occasional jobs.

\section{Determination of the technical actions}

This risk assessment was carried out in a plant for the processing of hazelnuts. Here some workers are engaged in the sorting of hazelnuts.

In order to determine the number of actions carried out, the work shift was studied by analyzing the operations carried out, including the work breaks and their durations (Tables 2 and 3 ).

The tasks were then analysed by focusing on the different movements performed by the upper limbs. A video camera was used to record the workers at work, and videos then analyzed in slow motion in the laboratory. Camera position was changed several times during the work (videotaping simultaneously both from sagittal and frontal view) in order to have an overall view of the worker's movements. The workers were videotaped for at least one hour while performing a typical work routine. The number of actions carried out was established from a period of observation representative of the whole shift (one hour per site). The calculation of the actions needed to carry out a cycle was determined by slow-motion observation and the number of actions performed by the worker per minute $(F F)$ was calculated with the following equation:

$$
F F=\frac{N T C \times 60}{F C T} \text { (actions } / \text { min) }
$$

where $N T C$ is the number of technical actions (for the upper limb) needed to carry out the task during one cycle, FCT is the foreseeable duration of the cycle time in seconds, and 60 is a conversion factor (seconds to minutes). The $F F$ calculation was repeated for both upper limbs. The overall number of actual technical actions (ATA) needed in a shift was calculated with the following equation:

$A T A=F F \times D$ (actions/shift)

where $D$ is the shift duration (in min).

\section{Force, posture, additional, and repetitiveness factors}

One of the complementary variables to be defined concerns the amount of force needed to perform an action. The greater the force required, the less frequent the number of actions that can be carried out to maintain the same level of risk (CEN, 2007). In order to characterize this variable, the OCRA standard uses Borg scale which measures perceived exertion. The worker assigns for each action a score according to the scale in Table 4; on the basis of Borg score, the multiplicative factor FoM is then assigned (Table 5).

Concerning the posture factor, in the literature the presence of repetitive movements for at least $2 / 3$ of the work cycle is considered an element of risk in itself, as is the presence of movements that exceed the articular range by over $50 \%$ (Figure 3 ) for $1 / 3$ of the work cycle.

In OCRA model, as the movements of the shoulders, elbows, wrists, and hands were observed, we also evaluated the simultaneous presence of complementary elements of risk, such as jerky movements, shocks, and vibrations. When a job is analyzed, every gesture is included, and a risk score is assigned to each movement. At the end of the analysis of awkward postures, in order to calculate the equation, the lowest PoM multiplier (Table 6) is selected in accordance with the postures and movements of the elbow, wrist, and hand (type of grip).

Next, a score is assigned for the complementary elements that is equal to 1 when they are irrelevant and decreases to as low as 0.80 when they are detected through the whole cycle. If additional factors as listed above are absent throughout most of the task, then the additional factor multiplier (AdM) equals 1. Otherwise, AdM equals (CEN, 2007):

- 1 if additional factors are present for less than $25 \%$ of the cycle;

- 0.95 if additional factors are present for $1 / 3$ (25\% to $50 \%)$ of the cycle;

- $\quad 0.90$ if additional factors are present for $2 / 3$ (51\% to $80 \%)$ of the cycle;

Table 2. Study of work shift (workers n. 1, 9 and 10).

\begin{tabular}{llcc} 
Job & \multicolumn{1}{c}{$\begin{array}{c}\text { Description } \\
\text { Sorting line }\end{array}$} & $\begin{array}{c}\text { Duration } \\
(\mathrm{min})\end{array}$ & $\begin{array}{c}\text { Type of job } \\
\text { (repetitive/not repetitive) }\end{array}$ \\
\hline First break & Hazelnut sorting on conveyor belt & 210 & Repetitive \\
Second break & Lunch break established by worker & 40 & Recovery time \\
\hline Total minutes of actual work and breaks & Breaks due to cleaning, supply, etc. & 110 & Recovery time \\
\hline
\end{tabular}

Table 3. Study of work shift (worker n. 8).

\begin{tabular}{lccc} 
Job & \multicolumn{1}{c}{$\begin{array}{c}\text { Description } \\
\text { Sorting line }\end{array}$} & $\begin{array}{c}\text { Duration } \\
(\mathrm{min})\end{array}$ & $\begin{array}{c}\text { Type of job } \\
\text { (repetitive/not repetitive) }\end{array}$ \\
\hline First break & Hazelnut sorting on conveyor belt & 320 & Repetitive \\
Total minutes of actual work and breaks & Lunch break established by worker & 40 & Recovery time \\
\hline
\end{tabular}


- 0.80 if additional factors are present for $3 / 3(>80 \%)$ of the cycle.

With regard to the repetitiveness multiplier (ReM), when the task requires the performance of the same technical actions of the upper limbs for at least $50 \%$ of the cycle time or when the cycle time is shorter than 15 seconds, the corresponding multiplier factor $(R e M)$ is 0.7 . Otherwise, ReM is equal to 1 (CEN, 2007).

\section{Recovery period factor}

In recovery periods there is a substantial inactivity of the muscular groups used in repetitive movements. Rest breaks, such as the lunch break, are considered recovery periods, as well as periods when the worker performs other jobs without using the muscle group analyzed. Periods when these muscle groups are at rest, provided that they are at rest for at least 10 to 20 seconds, as suggested by the OCRA authors, are considered recovery periods. According to the number of working hours that do not have adequate recovery periods, the value of the multiplicative factor $(R c M)$ to be used in Eq. 2 is assigned as shown in Tables 7 and 8 . The multiplier for the overall duration of repetitive tasks (DuM) during a shift is determined in relation to the overall daily duration (in minutes) of manual repetitive tasks (Table 9 ).

\section{Results}

Table 10 shows, for each worker: the multiplicative coefficients for risk factors (FoM, PoM, AdM, and ReM), the multiplier for the "lack of recovery period" risk factor $(R c M)$, the multiplier for the overall duration of repetitive tasks during a shift $(D u M)$, the net duration of the repetitive task in minutes $(D)$, the number of actions performed per minute $(F F)$, the overall number of actual technical actions needed in the workers' shift (ATA) and the overall number of reference technical actions (RTA). The values for right and left limbs are showed.

Table 11 shows the results of the risk assessment, with the OCRA index calculated for each worker.

The OCRA index values up to 2.2 are acceptable; values between 2.3 and 3.5 represent a possibility of risk, and values higher than 3.5 are considered unacceptable (more than 4.5 the risk is high, more than 9 the risk is very high), and therefore the way in which the job is carried out should be modified.

\section{Conclusions}

The research results indicate that the manual sorting of hazelnuts constitutes a situation of high risk due to repetitive movements of the upper limbs.

Looking at the values in Table 11, it is clear that the risk tends to increase with work experience in the specific task: the latter, in fact,
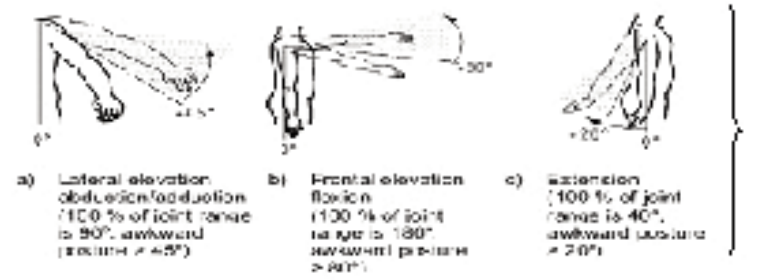

A

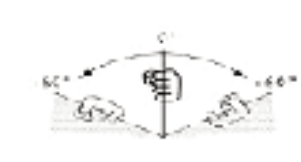

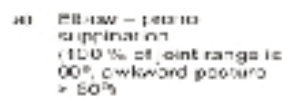

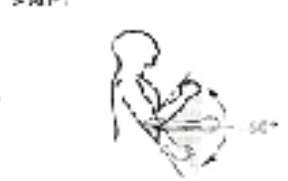

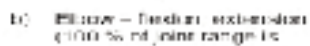
t is as, ankwars posture

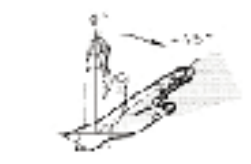

or Wrizk Pamce nowicn 100 is of idint ranos is

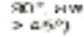

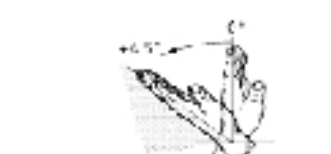

i d) Wdit Dorewl ontonoion.

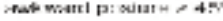

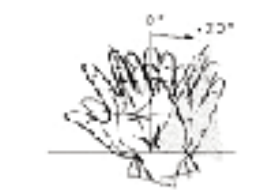

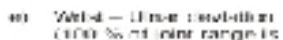

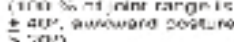

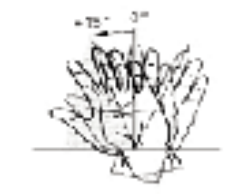

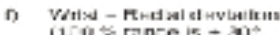

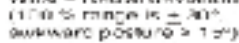

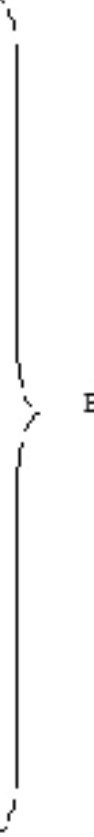

Figure 3. Shoulder postures and movements (A) and elbow and wrist postures and movements (B) (CEN, 2007).

Table 4. Borg scale for the evaluation of muscular force.

\begin{tabular}{lccc} 
Score & Description & Score & Description \\
0 & Completely absent & 5 & Strong \\
0.5 & Extremely light & 6 & Strong $(+)$ \\
\hline 1 & Very light & 7 & Very strong \\
2 & Light & 8 & Very strong (+) \\
\hline 3 & Moderate (modest) & 9 & Very strong (++) \\
4 & Modest $(+)$ & 10 & Maximum \\
\hline
\end{tabular}

Table 5. Correspondence between Borg scale score and the multiplicative factor FoM.

\begin{tabular}{|c|c|c|c|c|c|c|c|c|c|c|}
\hline & \multicolumn{9}{|c|}{ Average perceived exertion } & \multirow[b]{2}{*}{$\geq 5$} \\
\hline & $\leq 0.5$ & 1 & 1.5 & 2 & 2.5 & 3 & 3.5 & 4 & 4.5 & \\
\hline Force factor $(F o M)$ & 10.85 & 0.75 & 0.65 & 0.55 & 0.45 & 0.35 & 0.2 & 0.1 & 0.01 & \\
\hline
\end{tabular}


Table 6. Multipliers (PoM) for awkward postures

Awkward posture (Figure 3)

$1 \%$ to $24 \%$

Portion of the cycle time

$(<1 / 3)$

$25 \%$ to $50 \%$

(1/3)

$51 \%$ to $80 \%$

(2/3)

Elbow supination $\left(>60^{\circ}\right)$

Wrist extension $\left(>45^{\circ}\right)$ or flexion $\left(>45^{\circ}\right)$

Hand pinch or hook grip or palmar grip (wide span)

1

0.7

0.6

0.5

Elbow pronation $\left(>60^{\circ}\right)$ or flexion/extension $\left(>60^{\circ}\right)$

Wrist radio-ulnar deviation $\left(>20^{\circ}\right)$

Hand power grip with narrow span $(<2 \mathrm{~cm})$

1

1 0.7

Table 7. Risk index relative to the relationship between work and rest periods.

\begin{tabular}{lcc} 
Work/Recovery ratio & Recovery & Risk \\
From $5 / 1$ to $6 / 1$ & Adequate & 0 \\
From $7 / 1$ to $11 / 1$ & Not satisfactory & 0.5 \\
\hline$>11 / 1$ & Not sufficient & 1 \\
\hline
\end{tabular}

Table 8. Recovery factor related to the presence or absence of adequate recovery periods.

\begin{tabular}{|c|c|c|c|c|c|c|c|c|c|}
\hline \multicolumn{10}{|c|}{ Number of hours without adequate recovery periods } \\
\hline & 0 & 1 & 2 & 3 & 4 & 5 & 6 & 7 & 8 \\
\hline $\begin{array}{l}\text { Multiplicative } \\
\text { factor }(R C M)\end{array}$ & 1 & 0.90 & 0.80 & 0.70 & 0.60 & 0.45 & 0.25 & 0.10 & 0 \\
\hline
\end{tabular}

Table 9. Elements for the determination of the duration multiplier $(D u M)$.

\begin{tabular}{|c|c|c|c|c|}
\hline & \multicolumn{4}{|c|}{ Total time devoted to repetitive tasks during shift (min) } \\
\hline & $\geq 180$ & 181 to 240 & 240 to 480 & $>480$ \\
\hline Duration multiplier (DuM) & 2 & 1.5 & 1 & 0.5 \\
\hline
\end{tabular}

Table 10. Elements for calculating the OCRA index.

\begin{tabular}{|c|c|c|c|c|c|c|c|c|c|c|c|}
\hline Worker n. & Limb* & $\operatorname{ReM}$ & PoM & FoM & $A d M$ & D (min) & $F F($ act $/ \mathrm{min})$ & ReM & DuM & ATA & $R T A$ \\
\hline \multirow[t]{2}{*}{1} & $\mathrm{R}$ & 1 & 0.6 & 1 & 0.9 & 210 & 116 & 0.9 & 1.5 & 24360 & 4593 \\
\hline & $\mathrm{L}$ & 1 & 0.6 & 1 & 0.9 & 210 & 62 & 0.9 & 1.5 & 13020 & 4593 \\
\hline \multirow[t]{2}{*}{9} & $\mathrm{R}$ & 0.7 & 0.7 & 1 & 0.9 & 210 & 131 & 0.8 & 1.5 & 27510 & 3149 \\
\hline & $\mathrm{L}$ & 0.7 & 0.7 & 1 & 0.9 & 210 & 85 & 0.8 & 1.5 & 17850 & 3149 \\
\hline \multirow[t]{2}{*}{10} & $\mathrm{R}$ & 0.7 & 0.6 & 1 & 0.9 & 210 & 120 & 0.9 & 1.5 & 25200 & 3215 \\
\hline & $\mathrm{L}$ & 0.7 & 0.6 & 1 & 0.9 & 210 & 112 & 0.9 & 1.5 & 23520 & 3215 \\
\hline \multirow[t]{2}{*}{8} & $\mathrm{R}$ & 0.7 & 0.6 & 1 & 0.9 & 320 & 120 & 0.7 & 1.5 & 38400 & 3810 \\
\hline & $\mathrm{L}$ & 0.7 & 0.6 & 1 & 0.9 & 320 & 112 & 0.7 & 1.5 & 35840 & 3810 \\
\hline
\end{tabular}

Table 11. Risk assessment with OCRA index.

\begin{tabular}{|c|c|c|c|}
\hline Worker n. & Limb* & OCRA index & Risk \\
\hline 1 & $\begin{array}{l}\mathrm{R} \\
\mathrm{L}\end{array}$ & $\begin{array}{l}5.3 \\
2.8\end{array}$ & $\begin{array}{l}\text { High } \\
\text { Light }\end{array}$ \\
\hline 9 & $\begin{array}{l}\mathrm{R} \\
\mathrm{L}\end{array}$ & $\begin{array}{l}8.7 \\
5.7\end{array}$ & $\begin{array}{l}\text { High } \\
\text { High }\end{array}$ \\
\hline 10 & $\begin{array}{l}\mathrm{R} \\
\mathrm{L}\end{array}$ & $\begin{array}{l}7.8 \\
7.3\end{array}$ & $\begin{array}{l}\text { High } \\
\text { High }\end{array}$ \\
\hline 8 & $\begin{array}{l}\mathrm{R} \\
\mathrm{L}\end{array}$ & $\begin{array}{c}10.1 \\
9.4\end{array}$ & $\begin{array}{l}\text { Very high } \\
\text { Very high }\end{array}$ \\
\hline
\end{tabular}

${ }^{*} \mathrm{R}=$ right; $\mathrm{L}=$ left.

open Access [Journal of Agricultural Engineering 2013; volume XLIV(s2):e130] 
leads to a natural increase in the frequency of movements (actions per minute) with a consequent increase of OCRA index.

Given the existence of a risk situation related to repetitive activities, the company should plan and implement new prevention strategies. These should consider the fact that the factors that have the greatest impact on the risk associated with repetitive movements, are the incorrect posture and the deficiency of recovery time. On this basis we can identify some measures:

creating a more comfortable workplace, able to meet all the ergonomic standards (e.g. workstations adjustable in height depending on the height of workers);

ensuring a higher frequency of rests (recovery time) spread during the workday;

reducing the duration of repetitive work;

improve the structural design of the working environment, for example by providing a second conveyor belt to carry away the rejects, or wider wastebaskets for rejects, in order to facilitate their release by workers.

Finally, the training of workers on the correct methods of work and the health surveillance of workers themselves are very important for the prevention of WMSDs.

\section{References}

ACGIH. Threshold limit value for chemical substances and physical agents and biological exposure indices. Cincinnati, Ohio: American Conference of Governmental Industrial Hygienists. 2001.

Apostoli, P., Bazzini, G., Sala, E., Imbriani, M. La versione italiana "OREGE" (Outil de Repérage et d'Evaluation des Gestes) dell'INRS (Institut National de Recherche et de Sécurité) per la valutazione dei disturbi muscolo-scheletrici dell'arto superiore. G. Ital. Med. Lav. Erg. 2002;24: 3-25.

Baar, A.E., Barbe, M.F., Clark, B.D. Work-related musculoskeletal disorders of the hand and wrist: epidemiology, pathophysiology, and sensorimotor changes. The Journal of Orthopaedic and Sports Physical Therapy. 2004;34:610-27.

Barr, A.E., Barbe, M.F. Pathophysiological tissue changes associated with repetitive movement: a review of the evidence. Journal of the American Physical Therapy Association. 2002;82: 173-87.

Borg, G. A. V. Psychophysical bases of perceived exertion. Med. Sci. Sports Exercise 1982;14: 377-81.

Cecchini, M., Bedini, R., Colantoni, A., Menghini, G., Monarca, D. Repetitive movements of upper limbs and risk of musculoskeletal disorders for workers during the cheese production in an Italian agro-food factory. In Proc. Irish Meeting on Agriculture Occupational Safety and Health. Dublin (Ireland), 22 - 24 August 2011.

Cecchini, M., Colantoni, A., Massantini, R., Monarca, D. The risk of musculoskeletal disorders for workers due to repetitive movements during tomato harvesting. J Agric Saf Health. 2010;16: 87-98.

CEN. EN 1005-5 Safety of machinery - Human physical performance Part 5: Risk assessment for repetitive handling at high frequency. 2007. Brussels, Belgium: European Committee for Standardization.

Colantoni, A., Marucci, A., Monarca, D., Pagniello, B., Cecchini, M., Bedini, R. The risk of musculoskeletal disorders due to repetitive movements of upper limbs for workers employed to vegetable graft- ing. Journal of Food Agriculture and Environment. 2012;10: 14-8.

Colombini, D., Occhipinti, E. Application of concise exposure index (OCRA) to tasks involving repetitive movements of the upper limbs in various industrial settings: Preliminary experience and validation. Occup. Health and Ind. Med. 1997;37: 76-9.

Colombini, D., Occhipinti, E. Preventing upper limb work-related musculoskeletal disorders (UL-WMSDS): New approaches in job (re)design and current trends in standardization. Appl. Ergon. 2006;37: 441-50.

Davis, T.R.C. Do repetitive tasks give rise to musculoskeletal disorders? Occupational Medicine (Lond) 1999;49: 257-8.

Grieco, A. Application of the concise exposure index (OCRA) to tasks involving repetitive movements of the upper limbs in a variety of manufacturing industries: Preliminary validations. Ergonomics. 1998;41: 1347-56.

INAIL. Rapporto annuale 2012.

INRS. Method de prevention des troubles musculosquelettiques du membre superiore et outils simplex. Doc. Med. Trav. 2000;83: 187223.

ISO. ISO 11228-3 Ergonomics - Manual handling - Part 3: Handling of low loads at high frequency. International Organization for Standardization. 2009.

Leclerc, A., Landre, M.F., Chastang, J.F., Niedhammer, I., Roquelaure, Y. Upper-limb disorders in repetitive work. Scandinavian Journal of Work Environment \& Health. 2001;27:268-78.

Mc Atamney, L., Corlett, E. N. RULA: A survey method for the investigation of work-related upper limb disorders. Appl. Ergon. 1993;24: 91-9.

Merseburger, A. Movimenti ripetitivi degli arti superiori: risultati della valutazione dell'esposizione e dell'indagine clinica nella selezione e confezionamento delle mele. La Medicina del Lavoro. 1996;87: 603-12.

Monarca, D., Cecchini, M., Colantoni, A. 2011. Working posture, repetitive movements of upper limbs and risk of musculoskeletal disorders for workers during the cheese production in an Italian agrofood factory. Vienna (Austria), 29 June- 1 July 2011.

Monarca, D., Cecchini, M., Panaro, V. Analisi dei rischi di affezioni muscolo scheletriche da lavoro ripetitivo per gli addetti ad alcune operazioni agricole e agroindustriali. In Proc. AIIA 2001 Ingegneria Agraria per lo Sviluppo dei Paesi del Mediterraneo.

Moore, J. S., Garg, A. The strain index: A proposed method to analyze jobs for risk of distal upper extremity disorders. American Ind. Hyg. Assoc. J. 1995;56: 443-58.

Occhipinti, E. OCRA, a concise index for the assessment of exposure to repetitive movements of the upper limbs. Ergonomics. 1998;41: 1290-311.

Occhipinti, E., Colombini D. Proposta di un indice sintetico per la valutazione dell'esposizione a movimenti ripetitivi degli arti superiori (OCRA index). La Medicina del Lavoro. 1996;87: 526-48.

Occhipinti, E., Colombini, D. Alterazioni muscolo scheletriche degli arti superiori da sovraccarico biomeccanico: Metodi e criteri per l'inquadramento dell'esposizione lavorativa. La Medicina del Lavoro. 1996;87: 491-525.

Occhipinti, E., Colombini, D. Proposed concise index for the assessment of exposure to repetitive movements of the upper limbs. Occup. Health and Ind. Med. 1997;37: 73-7.

Schneider, S. OSHA's draft standard for prevention of work-related musculoskeletal disorders. Applied Occup. Environ. Hygiene 1995;10: 665-76. 